\title{
Accuracy of Ultrasound in Estimating Fetal Weight at Term
}

\author{
SAAD MOKHTAR, M.Sc.; MOHAMED S.M. FOUAD, M.D. and MAHMOUD S. ISMAIL, M.D. \\ The Department of Obstetrics and Gynecology, Faculty of Medicine, Al-Azhar University, Cairo, Egypt
}

\begin{abstract}
Background: To compare the accuracy of different sonographic formulae for fetal weight estimation at term.

Material and Methods: Comparative cross-sectional study to evaluate 8 different formulae using 300 sonographic weight estimations performed within 24 hours before delivery. Using correlation coefficient, regression analysis and Bland and Altman method, to compare between the studied formulae with each other and knowing the effect the different fetal biometric indices on accuracy of estimates by ultrasound.
\end{abstract}

Results: A considerable variation in the accuracy of the different formulae was found. For Birth Weights (BWs) in the range of 2500 to $3500 \mathrm{~g}$, formulae based on 3 or 4 fetal biometric indices were significantly more accurate than formulae that incorporated only 1 or 2 indices. The accuracy of formulae decreased at the extreme of birth weight > $4000 \mathrm{gs}$, leading to underestimation of ABW (actual birth weight).

Conclusion: We conclude that to improve the accuracy of fetal weight estimation, sonographic formulae that are based on 3 or 4 fetal biometric indices should be preferred.

Key Words: Ultrasound - Birth weight-Term pregnancy.

\section{Introduction}

THE ultrasound estimation of fetal weight in term pregnancies is used to determine fetal growth, and this may affect the timing and route of delivery [1-3]. Although antenatal care has focused more on the diagnosis of fetal growth restriction and fetal macrosomia, the delivery of macrosomic infants is associated with higher rates of adverse outcomes for both mother and infant in comparison to the delivery of normal weight infants [4-7]. Ultrasound of fetal weight estimations is undertaken as part of the routine antenatal care of pregnant women, accurate estimation of fetal weight now has an important role in routine antenatal care and for detection of fetal growth abnormalities $[4,8]$, for

Correspondence to: Dr. Saad Mokhtar E-Mail: Ictu777@yahoo.com this reason, researchers have invested much effort in creating formulae that would accurately predict fetal weight. These formulae are mainly based on different combinations of sonographically measured fetal biometric indices, mainly Abdominal Circumference (AC), Femur Length (FL), Biparietal Diameter (BPD), and Head Circumference (HC) [9-12].

\section{Material and Methods}

Comparative cross-sectional study included 300 pregnant women aged between (16-40) years old who had single viable at term foetus one day prior elective C.S in Ahmed Maher Teaching Hospital from March 2017 to Sept. 2017. Pregnant women with fetal malformation were excluded from this study. This study was approved by the Ethics Committee of our hospital.

Every patient in our study was explained in details regarding the nature of the study and its benefits and only those who agreed to participate in the study were be included, all patients were subjected to a written informed consent after explaining the study and possible consequences in a way that they could understand. The fetal biometric measurements were be taken by highly trained Sonographers or obstetric specialists, within one day prior to delivery. The ultrasonographic measurements of BPD, HC, AC and FL were obtained using real-time, $B$ mode equipped with $3.5 \mathrm{MHz}$ abdominal probe. The actual birth weights were also entered into the data sheet after the delivery of the foetus. The participants were explained about the Ultrasound Scan examination (USS) and were asked to evacuate the urinary bladder before the scanning. The BPD, HC, AC and FL were measured in centimeters $(\mathrm{cm})$ and the fetal weight in grams. All examinations were performed using the same ultrasound machine and the same curvilinear trans- 
ducer probe. All measurements were made on the ultrasound machine on frozen images.

\section{Results}

As we use the (mean $\pm \mathrm{SD}$ ) and paired $t$-test ( $t$ and $p$-value) for comparison of each formulae to each other and with ABW to know which of any formula is significant or non-significant with ABW.

When we make all patients as one group, the mean weight values of Warsof and Merz formulae are non-significant with ABW, where their mean weight \pm Standard Deviation (SD) equal to $3555.425 \pm 199.380 \mathrm{~g}$ and $3568.092 \pm 239.958 \mathrm{~g}$, respectively and $p$-value equal to $0.290,0.497$ respectively where other formulae is significant with ABW this is not mean the accuracy of the formulae but signification value with $\mathrm{ABW}$ results this mean that the mean weight of Warsof formula is the much non significant value- $(p$-value $=0.290)$ among all formulae with ABW.

In weight category $(>3.5-4 \mathrm{~kg})$ the accuracy of studied formulae to predict birth weight within $\pm 5 \%$ or $\pm 10 \%$ of the actual birth weight as the following, the prediction rate of Merz (AC, BPD) formula to predict birth weight within $\pm 10 \%$ of the actual birth weight $(>3.5-4 \mathrm{~kg})$ increase up to $(100 \%)$ in this weight category $(>3.5-4 \mathrm{~kg})$ followed by Shepard formula equal to $(95.5 \%)$, Hadlock I equal to $(93.8 \%)$ and Hadlock III equal to $(91.84 \%)$.

In weight category $(>4 \mathrm{~kg}$ ) the accuracy of studied formulae to predict birth weight within $\pm 5 \%$ or $\pm 10 \%$ of the actual birth weight $(>4 \mathrm{~kg})$ the best prediction rate within $\pm 10 \%$ of the actual birth weight is Shepard formula equal to $(89.5 \%)$ followed by Merz (AC, BPD) formula equal to $(42.11 \%)$ and Warsof $(\mathrm{AC})$ equal to $(42.10 \%)$.

Table (1): Fraction estimate in woo formula.

\begin{tabular}{|c|c|c|c|c|c|c|c|}
\hline \multirow{2}{*}{ Woo } & \multicolumn{5}{|c|}{$\mathrm{Wt}$} & \multicolumn{2}{|c|}{ Chi-square } \\
\hline & $<3 \mathrm{~kg}$ & $3-3.5 \mathrm{~kg}$ & $3.5-4 \mathrm{~kg}$ & $>4 \mathrm{~kg}$ & Total & $x^{2}$ & $p$-value \\
\hline \multicolumn{8}{|c|}{$<5 \%$ : } \\
\hline $\mathrm{N}$ & 12 & 52 & 37 & 2 & 103 & 136.471 & 0.000 \\
\hline$\%$ & $80.0 \%$ & $57.8 \%$ & $31.4 \%$ & $2.6 \%$ & $34.3 \%$ & & \\
\hline \multicolumn{8}{|c|}{$5-10 \%$} \\
\hline $\mathrm{N}$ & 3 & 28 & 33 & 10 & 74 & & \\
\hline$\%$ & $20.0 \%$ & $31.1 \%$ & $28.0 \%$ & $13.0 \%$ & $24.7 \%$ & & \\
\hline \multicolumn{8}{|c|}{$10-15 \%:$} \\
\hline $\mathrm{N}$ & 0 & 10 & 36 & 28 & 74 & & \\
\hline$\%$ & $0.0 \%$ & $11.1 \%$ & $30.5 \%$ & $36.4 \%$ & $24.7 \%$ & & \\
\hline \multicolumn{8}{|c|}{$>15 \%:$} \\
\hline $\mathrm{N}$ & 0 & 0 & 12 & 37 & 49 & & \\
\hline$\%$ & $0.0 \%$ & $0.0 \%$ & $10.2 \%$ & $48.1 \%$ & $16.3 \%$ & & \\
\hline
\end{tabular}

Table (2): Fraction estimate in Hadlock I formula.

\begin{tabular}{|c|c|c|c|c|c|c|c|}
\hline \multirow{2}{*}{$\begin{array}{l}\text { Hadlock } \\
\text { I }\end{array}$} & \multicolumn{5}{|c|}{$\mathrm{Wt}$} & \multicolumn{2}{|c|}{ Chi-square } \\
\hline & $<3 \mathrm{~kg}$ & $3-3.5 \mathrm{~kg}$ & $3.5-4 \mathrm{~kg}$ & $>4 \mathrm{~kg}$ & Total & $x^{2}$ & $p$-value \\
\hline \multicolumn{8}{|l|}{$<5 \%$} \\
\hline $\mathrm{N}$ & 3 & 67 & 38 & 3 & 112 & 258.316 & 0.000 \\
\hline$\%$ & $14.3 \%$ & $84.8 \%$ & $36.9 \%$ & $3.1 \%$ & $37.3 \%$ & & \\
\hline \multicolumn{8}{|l|}{$5-10 \%:$} \\
\hline $\mathrm{N}$ & 7 & 5 & 54 & 12 & 78 & & \\
\hline$\%$ & $33.3 \%$ & $6.3 \%$ & $52.4 \%$ & $12.5 \%$ & $26.0 \%$ & & \\
\hline \multicolumn{8}{|l|}{$10-15 \%:$} \\
\hline $\mathrm{N}$ & 11 & 7 & 11 & 33 & 62 & & \\
\hline$\%$ & $52.4 \%$ & $8.9 \%$ & $10.7 \%$ & $34.4 \%$ & $20.7 \%$ & & \\
\hline \multicolumn{8}{|l|}{$>15 \%$} \\
\hline $\mathrm{N}$ & 0 & 0 & 0 & 48 & 48 & & \\
\hline$\%$ & $0.0 \%$ & $0.0 \%$ & $0.0 \%$ & $50.0 \%$ & $16.0 \%$ & & \\
\hline
\end{tabular}

Table (3): Fraction estimate in Warsof formula.

\begin{tabular}{clllllll}
\hline \multirow{2}{*}{ Warsof } & \multicolumn{5}{c}{$\mathrm{Wt}$} & \multicolumn{3}{c}{ Chi-square } \\
\cline { 2 - 7 } & $<3 \mathrm{~kg}$ & $3-3.5 \mathrm{~kg}$ & $3.5-4 \mathrm{~kg}$ & $>4 \mathrm{~kg}$ & Total & $\chi^{2}$ & $p$-value \\
\hline$<5 \%:$ & & & & & & & \\
$\mathrm{N}$ & 0 & 38 & 61 & 2 & 101 & 183.683 & 0.000 \\
$\%$ & $0.0 \%$ & $40.0 \%$ & $61.0 \%$ & $3.0 \%$ & $33.7 \%$ & & \\
$5-10 \%:$ & & & & & & & \\
$\mathrm{N}$ & 0 & 44 & 24 & 15 & 83 & & \\
$\%$ & $0.0 \%$ & $46.3 \%$ & $24.0 \%$ & $22.4 \%$ & $27.7 \%$ & & \\
$10-15 \%:$ & & & & & & & \\
$\mathrm{N}$ & 15 & 7 & 15 & 26 & 62 & & \\
$\%$ & $38.5 \%$ & $7.4 \%$ & $15.0 \%$ & $38.8 \%$ & $20.7 \%$ & \\
$>15 \%:$ & & & & & & \\
$\mathrm{N}$ & 24 & 6 & 0 & 24 & 54 & \\
$\%$ & 61.5 & $6.3 \%$ & $0.0 \%$ & 35.8 & 18.0 & \\
\hline
\end{tabular}

Table (4): Fraction estimate in Merz formula.

\begin{tabular}{|c|c|c|c|c|c|c|c|}
\hline \multirow{2}{*}{ Merz } & \multicolumn{5}{|c|}{$\mathrm{Wt}$} & \multicolumn{2}{|c|}{ Chi-square } \\
\hline & $<3 \mathrm{~kg}$ & $3-3.5 \mathrm{~kg}$ & $3.5-4 \mathrm{~kg}$ & $>4 \mathrm{~kg}$ & Total & $x^{2}$ & $p$-value \\
\hline \multicolumn{8}{|l|}{$<5 \%$} \\
\hline $\mathrm{N}$ & 0 & 43 & 59 & 3 & 106 & 177.351 & 0.000 \\
\hline$\%$ & $0.0 \%$ & $42.6 \%$ & $64.8 \%$ & $4.2 \%$ & $35.3 \%$ & & \\
\hline \multicolumn{8}{|c|}{$5-10 \%$} \\
\hline $\mathrm{N}$ & 4 & 34 & 32 & 13 & 84 & & \\
\hline$\%$ & $11.8 \%$ & $33.7 \%$ & $35.2 \%$ & $18.1 \%$ & $28.0 \%$ & & \\
\hline \multicolumn{8}{|c|}{$10-15 \%$} \\
\hline $\mathrm{N}$ & 20 & 4 & 0 & 36 & 60 & & \\
\hline$\%$ & $58.8 \%$ & $4.0 \%$ & $0.0 \%$ & $50.0 \%$ & $20.0 \%$ & & \\
\hline \multicolumn{8}{|c|}{$>15 \%$} \\
\hline $\mathrm{N}$ & 10 & 20 & 0 & 20 & 50 & & \\
\hline$\%$ & $29.4 \%$ & $19.8 \%$ & $0.0 \%$ & $27.8 \%$ & $16.7 \%$ & & \\
\hline
\end{tabular}


Table (5): Fraction estimate in Hadlock II formula.

\begin{tabular}{|c|c|c|c|c|c|c|c|}
\hline \multirow{2}{*}{$\begin{array}{l}\text { Hadlock } \\
\text { II }\end{array}$} & \multicolumn{5}{|c|}{ Wt } & \multicolumn{2}{|c|}{ Chi-square } \\
\hline & $<3 \mathrm{~kg}$ & $3-3.5 \mathrm{~kg}$ & $3.5-4 \mathrm{~kg}$ & $>4 \mathrm{~kg}$ & Total & $x^{2}$ & $p$-value \\
\hline \multicolumn{8}{|l|}{$<5 \%$ : } \\
\hline $\mathrm{N}$ & 5 & 61 & 37 & 5 & 109 & 210.799 & 0.000 \\
\hline$\%$ & $27.8 \%$ & $75.3 \%$ & $34.6 \%$ & $5.3 \%$ & $36.3 \%$ & & \\
\hline \multicolumn{8}{|l|}{ 5-10\%: } \\
\hline $\mathrm{N}$ & 9 & 16 & 47 & 9 & 81 & & \\
\hline$\%$ & $50.0 \%$ & $19.8 \%$ & $43.9 \%$ & $9.6 \%$ & $27.0 \%$ & & \\
\hline \multicolumn{8}{|l|}{ 10-15\%: } \\
\hline $\mathrm{N}$ & 4 & 4 & 23 & 31 & 61 & & \\
\hline$\%$ & $22.2 \%$ & $4.9 \%$ & $21.5 \%$ & $33.0 \%$ & $20.3 \%$ & & \\
\hline \multicolumn{8}{|l|}{$>15 \%:$} \\
\hline $\mathrm{N}$ & 0 & 0 & 0 & 49 & 49 & & \\
\hline$\%$ & $0.0 \%$ & $0.0 \%$ & $0.0 \%$ & $52.1 \%$ & $16.3 \%$ & & \\
\hline
\end{tabular}

Table (6): Fraction estimate in Hadlock IV formula.

\begin{tabular}{|c|c|c|c|c|c|c|c|}
\hline \multirow{2}{*}{$\begin{array}{l}\text { Hadlock } \\
\text { IV }\end{array}$} & \multicolumn{5}{|c|}{ Wt } & \multicolumn{2}{|c|}{ Chi-square } \\
\hline & $<3 \mathrm{~kg}$ & $3-3.5 \mathrm{~kg}$ & $3.5-4 \mathrm{~kg}$ & $>4 \mathrm{~kg}$ & Total & $x^{2}$ & $p$-value \\
\hline \multicolumn{8}{|l|}{$<5 \%$ : } \\
\hline $\mathrm{N}$ & 8 & 58 & 42 & 5 & 113 & 138.712 & 0.000 \\
\hline$\%$ & $53.3 \%$ & $61.1 \%$ & $39.3 \%$ & $6.0 \%$ & $37.7 \%$ & & \\
\hline \multicolumn{8}{|l|}{$5-10 \%:$} \\
\hline $\mathrm{N}$ & 7 & 17 & 43 & 10 & 77 & & \\
\hline$\%$ & $46.7 \%$ & $17.9 \%$ & $40.2 \%$ & $12.0 \%$ & $25.7 \%$ & & \\
\hline \multicolumn{8}{|l|}{$10-15 \%$} \\
\hline $\mathrm{N}$ & 0 & 4 & 22 & 36 & 62 & & \\
\hline$\%$ & $0.0 \%$ & $4.2 \%$ & $20.6 \%$ & $43.4 \%$ & $20.7 \%$ & & \\
\hline \multicolumn{8}{|l|}{$>15 \%:$} \\
\hline $\mathrm{N}$ & 0 & 16 & 0 & 32 & 48 & & \\
\hline$\%$ & $0.0 \%$ & $16.8 \%$ & $0.0 \%$ & $38.6 \%$ & $16.0 \%$ & & \\
\hline
\end{tabular}

Table (7): Fraction estimate in Shepard formula.

\begin{tabular}{|c|c|c|c|c|c|c|c|}
\hline \multirow{2}{*}{ Shepard } & \multicolumn{5}{|c|}{$\mathrm{Wt}$} & \multicolumn{2}{|c|}{ Chi-square } \\
\hline & $<3 \mathrm{~kg}$ & $3-3.5 \mathrm{~kg}$ & $3.5-4 \mathrm{~kg}$ & $>4 \mathrm{~kg}$ & Total & $x^{2}$ & $p$-value \\
\hline \multicolumn{8}{|l|}{$<5 \%$} \\
\hline $\mathrm{N}$ & 3 & 36 & 50 & 19 & 108 & 51.339 & 0.000 \\
\hline$\%$ & $13.6 \%$ & $29.5 \%$ & $45.5 \%$ & $39.6 \%$ & $36.0 \%$ & & \\
\hline \multicolumn{8}{|l|}{$5-10 \%:$} \\
\hline $\mathrm{N}$ & 10 & 37 & 35 & 12 & 93 & & \\
\hline$\%$ & $45.5 \%$ & $30.3 \%$ & $31.8 \%$ & $25.0 \%$ & $31.0 \%$ & & \\
\hline \multicolumn{8}{|l|}{ 10-15\%: } \\
\hline $\mathrm{N}$ & 9 & 17 & 9 & 17 & 51 & & \\
\hline$\%$ & $40.9 \%$ & $13.9 \%$ & $8.2 \%$ & $35.4 \%$ & $17.0 \%$ & & \\
\hline \multicolumn{8}{|l|}{$>15 \%:$} \\
\hline $\mathrm{N}$ & 0 & 32 & 16 & 0 & 48 & & \\
\hline$\%$ & $0.0 \%$ & $26.2 \%$ & $14.5 \%$ & $0.0 \%$ & $16.0 \%$ & & \\
\hline
\end{tabular}

Table (8): Fraction estimate in Hadlock III formula.

\begin{tabular}{|c|c|c|c|c|c|c|c|}
\hline \multirow{2}{*}{$\begin{array}{l}\text { Hadlock } \\
\text { III }\end{array}$} & \multicolumn{5}{|c|}{ Wt } & \multicolumn{2}{|c|}{ Chi-square } \\
\hline & $<3 \mathrm{~kg}$ & $3-3.5 \mathrm{~kg}$ & $3.5-4 \mathrm{~kg}$ & $>4 \mathrm{~kg}$ & Total & $x^{2}$ & $p$-value \\
\hline \multicolumn{8}{|l|}{$<5 \%:$} \\
\hline $\mathrm{N}$ & 8 & 58 & 43 & 5 & 114 & 152.175 & 0.000 \\
\hline$\%$ & $53.3 \%$ & $61.1 \%$ & $41.3 \%$ & $5.8 \%$ & $38.0 \%$ & & \\
\hline \multicolumn{8}{|l|}{$5-10 \%:$} \\
\hline $\mathrm{N}$ & 7 & 17 & 45 & 9 & 78 & & \\
\hline$\%$ & $46.7 \%$ & $17.9 \%$ & $43.3 \%$ & $10.5 \%$ & $26.0 \%$ & & \\
\hline \multicolumn{8}{|l|}{ 10-15\%: } \\
\hline $\mathrm{N}$ & 0 & 4 & 16 & 40 & 60 & & \\
\hline$\%$ & $0.0 \%$ & $4.2 \%$ & $15.4 \%$ & $46.5 \%$ & $20.0 \%$ & & \\
\hline \multicolumn{8}{|l|}{$>15 \%:$} \\
\hline $\mathrm{N}$ & 0 & 16 & 0 & 32 & 48 & & \\
\hline$\%$ & $0.0 \%$ & $16.8 \%$ & $0.0 \%$ & $37.2 \%$ & $16.0 \%$ & & \\
\hline
\end{tabular}

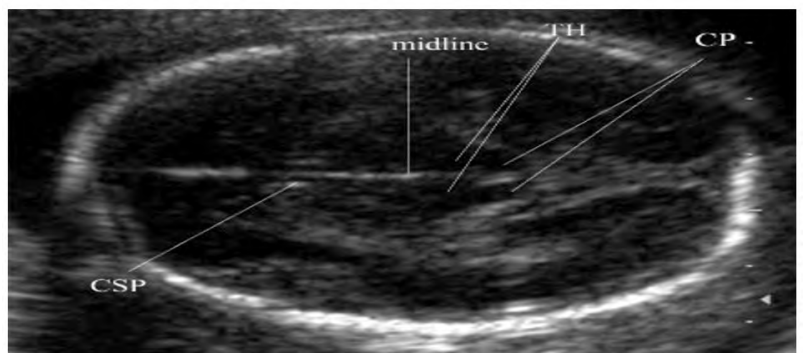

Fig. (1): Transverse section of the fetal head demonstrating the landmarks required to measure the BPD using the thalami view.

CP: Cerebral Peduncles.

CSP: Cavum Septum Pellucidum. TH: Thalami.

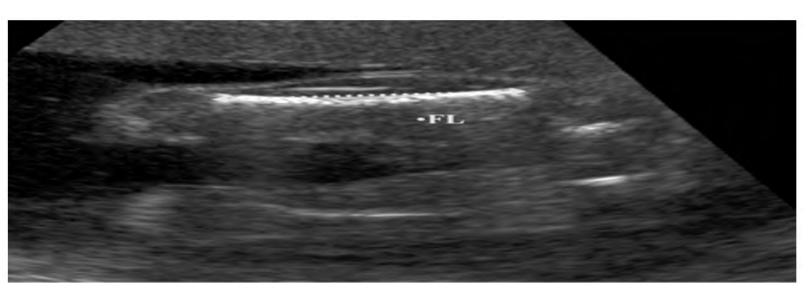

Fig. (2): Measurement of the fetal Femur Length (FL).

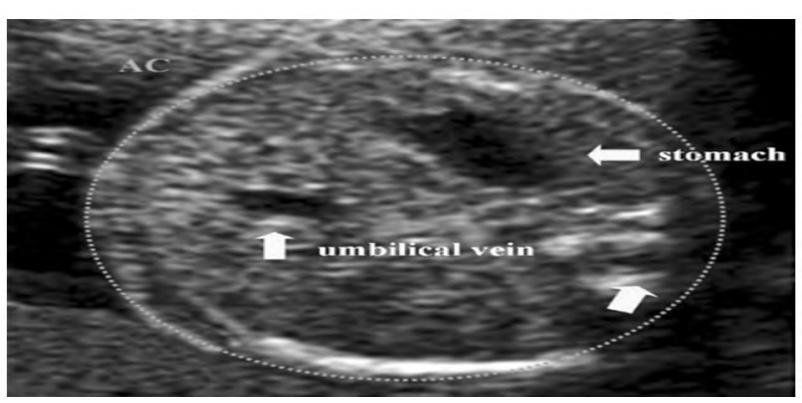

Fig. (3): Measurement of the fetal Abdominal Circumference (AC). 


\section{Statistical analysis:}

Analysis of data was done by IBM computer using SPSS Version 12. Results are expressed as mean \pm Standard Deviation (SD). Comparison between the mean values of different formulae was performed using paired differences (mean $\pm \mathrm{SD}$ ). Paired student $t$-test ( $t, p$-value), correlation coefficient and adjusted $\mathrm{R}$ square of regression analysis that compare the accuracy of different formulae, tendency of each formulae to overestimate or underestimate of the actual birth weight by blandAltman method, finally fraction estimates within $5 \%, 10 \%, 15 \%$ and more than $15 \%$ by Chi-square $(\chi, p$-value). Level of significance was set at $p<$ $0.05(5 \%), p$-value less or equal to 0.05 will be considered significant and less than 0.01 will be considered highly significant.

\section{Discussion}

Estimation of fetal weight by ultrasound is very important in affecting fetal, neonatal and maternal morbidity and mortality and those of high risk pregnancy such as intrauterine growth retardation, macrosomia and prematurity [5]. Estimation of fetal weight also is useful in management of small of date foetuses and macrosomic foetuses as well as mode of delivery.

In our study we evaluate eight different formulae in accuracy of estimation of fetal weight by ultrasound; all patients do ultrasound including fetal weight estimation within 24 hours prior to delivery, and measurement of actual fetal weight immediately after delivery and compare each individual formula with actual birth weight, we found the following.

In our study, the ultrasound estimations of fetal weight performed $\leq 24$ hours prior to delivery to avoid affection of time interval between the ultrasound measurement and measurement of actual birth weight some authors studying reliability of ultrasound estimation of fetal weight that include estimations of fetal weight that performed up to 14 days prior to delivery, Humphries et al., [13] and others have restricted their data to estimations performed within 7 days Wong and Chan [14] or within 3 days, Alsulyman et al., [15]; Ben-Haroush et al., [16]; Melamed et al., [17] or have attempted to correct for the time interval between the ultrasound and delivery by the addition of $25 \mathrm{~g}$ per day [18] or 12.4g or 13.0g per day [19]. Although fetal weight estimations made 4-6 days before delivery tended to slightly underestimate birth weight in Atalie et al., [20], the error was small $(-1.3 \pm 8.9 \%)$.
Barel et al., [21], the most accurate formulae are that using 3 fetal parameters or more followed by formulae that using abdominal circumference only and the formulae developed by Sabbagha et al., [22], are the most accurate formulae than other studied formulae, with a mean percent error of $-0.2 \%$ and up to $92 \%$ of estimates within $15 \%$ of birth weight $(p<.05)$.

Markus et al., [23], in fetuses weighing $\geq 4,000 \mathrm{~g}$. The best formulae are (Hart and (Hadlock IV contain HC, AC, FL) the systematic error not significantly different from 0 , and formulae that are based on 3 or 4 indices give the best results. Siemer et al., [24], showed that, the Merz \& Shepard formulae show accuracy in Macrosomic fetus. Markus et al., [23], Formula of Hadlock 2 (AC, FL) gives the best result at all. Marco et al., [25], formulae that based on head-abdomen-femur measurements showed the lowest mean absolute percentage error and more accuracy. The group of formulae that depend on Abdomen and Femur measurements are best in fetuses weighing more than $3,500 \mathrm{~g}(p<.01)$.

In our study the formulae (Woo, Hadlock III) that incorporate (AC, BPD, FL) are the most accurate formulae in overall weight range, where their correlation of EBW to ABW are $(0.860,0.858)$ respectively, and their fraction estimates within $10 \%$ of actual birth weight are the greatest among all evaluated formulae $100 \%$, this agreed with Hadlock et al., [26]; Melamed et al., [17]; Irina et al., [27].

While in weight range (3000-3500gs), we observe that, Hadlock II (AC, BPD, HC) achieved great improvement in the accuracy of EBW especially in the previous weight range (3000-3500gs) where its fraction estimates within $10 \%$ of actual birth weight is the greatest among all evaluated formulae that equal to $(97.73 \%)$ and its correlation with ABW (actual birth weight) in overall fetal weights equal to $(83.2 \%)$ and this formula tend to underestimate of $\mathrm{ABW}$, this results agree with many studies for example Markus et al., [23] that founded Hart and Hadlock II (AC, BPD, HC) formulae are the best accurate formulae that detect the birth weight above $3500 \mathrm{gs}$, and agree with Siemer et al., [24]

The combination of (AC, BPD, HC, FL) represented in our study by Hadlock IV where its accuracy improved in the following weight ranges $(\leq 3000 \mathrm{gs}$, <3000gs-3500gs, <3500-4000gs) where its fraction estimate within $10 \%$ of actual birth weight equal to $(100 \%, 95.46 \%, 87.75 \%$ respec- 
tively) and its correlation with actual birth weight equal to $(85.1 \%)$, adjusted $\mathrm{R}$ square $(72.1 \%)$ in overall weight range and adjusted $\mathrm{R}$ square equal to $(67.3 \%)<38$ weeks is the best $\mathrm{R}$ square $<38$ weeks (gestational age) among all studied formulae this agree with Kumara HP (2009) that found Hadlock IV is the best formula that detect fetal weight $<3000 g$ s in our study ( $r=85.1$ ) while in Kumara [28] $(r=83.6)$ this difference due to in our study all scans performed within 24 hours instead of 48 hours in Kumara, also our sample of patients greater than Kumara study.

We found that the accuracy the formulae that incorporate 3 or more fetal biometric indices more than 1 or 2 fetal biometric indices this agreed with Melamed et al., [17]; Hadlock et al., [26]; Siemer et al., [24]; Barel et al., [21]; Irina et al., [27]; Markus et al., [23], especially those utilizing abdominal circumference, biparietal diameter and femur length gives the most accurate prediction of fetal weight. Also we found that the accuracy of all studied formulae decreased at weight $<4000 \mathrm{gs}$ this agree with Melamed et al., [17]; Hadlock et al., [26]; Siemer et al., [24]; Barel et al., [21], the addition of FL to head and abdominal parameters is improving the estimated fetal weight results, Hadlock et al., [26], because femur length is directly related to the crown-heel length.

\section{Conclusion:}

We conclude that, the formulae that incorporate three or more fetal parameters give the most accurate prediction of fetal weight more than two or one fetal parameters. Also the formulae that incorporate multiple parameters especially those utilizing (AC, BPD and FL) give the most accurate prediction of fetal weight represented in our study by (Woo, Hadlock III).

In situations if the fetal head is deeply engaged making adequate head measurement difficult to measure it, we found the formulae that incorporate multiple parameters especially those utilizing (AC, $\mathrm{HC}$ and FL) give the most accurate prediction of fetal weight represented in our study by Hadlock II that incorporate (AC, BPD, HC) parameters while In situations of fetal weight > $4000 \mathrm{gs}$ Shepard and Merz formulae that incorporate (AC, BPD) give the most accurate prediction of fetal weight. The most effective fetal parameter in fetal weight estimation is abdominal circumference. Recognizing the accuracy and the tendency for underestimation or overestimation of each formula is important for the judicious interpretation of fetal weight estimations, especially at the extremes of fetal weight. In the end the validity and accuracy of any formulae in estimation of fetal weight by ultrasound in our study depend on gestational age and fetal weight categories at the time of scan and the position of the head especially if deeply engaged give chance for the formulae that contain $\mathrm{HC}$ in its equation to become more accurate.

\section{References}

1- BAMBERG C. and KALACHE K.D.: Prenatal diagnosis of fetal growth restriction, Semin. Fetal. Neonatal. Med., 9: 387-94, 2004.

2- CONWAY D.L.: Choosing route of delivery for the macrosomic infant of a diabetic mother: Cesarean section versus vaginal delivery, J. Matern. Fetal. Neonatal. Med., 12: 442-8, 2002.

3- PRESSMAN E.K., BIENSTOCK J.L. and BLAKEMORE K.J.: "Prediction of birth weight by ultrasound in the third trimester," Obstetrics \& Gynecology, 95 (4), 2000.

4- STOTLAND N.E., CAUGHEY A.B., BREED E.M. and ESCOBAR G.J.: Risk factors and obstetric complications associated with macrosomia. Int. J. Gynecol. Obstet., 87: 220-6, 2004.

5- WILLIAMS R.I., CUNNINGHAM G.C., HAINES W.E., NORRIS F.D. and TASHIRO M.: Fetal growth and perinatal viability in Carlifonia. Obstet. Gynaecol., 50: 62463, 1982.

6- IRION O. and BOULVAIN M.: Induction of labour for suspected fetal macrosomia, The Cochrane Library, Issue 1, 2003; http://update softare.com [Accessed 25 January 2003].

7- JOLLY M.C., SEBIRE N.J., HARRIS J.P., et al.: Risk factors for macrosomia and its clinical consequences: A study of 350,311 pregnancies. Eur. J. Obstet. Gynecol. Reprod. Biol., 10 (111): 9-14, 2003.

8- COOMARASAMY A., CONNOCK M., THORNTON J. and KHAN K.S.: Accuracy of ultrasound biometry in the prediction of macrosomia: A systematic quantitative review. BJOG. Nov., 112 (11): 1461-6. [Medline], 2005.

9- SMITH G.C., SMITH M.F., Mc NAY M.B. and FLEMING J.E.: The relation between fetal abdominal circumference and birth weight: Findings in 3512 pregnancies, $\mathrm{Br}$. J. Obstet. Gynaecol., 104: 186-90, 1997.

10- COMBS C.A., JAEKLE R.K., ROSENN B., POPE M., MIODOVNIK M. and SIDDIQI T.A.: Sonographic estimation of fetal weight based on a model of fetal volume, Obstet. Gynecol., 82: 365-70, 1993.

11- HART N., HILBERT A., MEURER B., SCHRAUDER M., SCHMID M., SIEMER J., et al.: Macrosomia: A new formula for optimized fetal weight estimation, Ultrasound Obstet. Gynecol., 35: 42-7, 2010.

12- DUDLEY N.J.: Systematic review of the ultrasound estimation of fetal weight, Ultrasound Obstet. Gynecol., 25: 80-9, 2005.

13-HUMPHRIES J., REYNOLDS D., BELL-SCARBROUGH L., et al.: Sonographic estimate of birth weight: Relative accuracy of Sonographers versus maternal-fetal medicine specialists, J. Matern. Fetal. Neonatal. Med., 11: 108-12, 2002. 
14- WONG S.F., CHAN F.Y., CINCOTTA R.B., et al.: Sonographic estimation of fetal weight in macrosomic fetuses: Diabetic versus non-diabetic pregnancies, Aust. N. Z. J. Obstet. Gynaecol., 41: 429-32, 2001.

15-ALSULYMAN O.M., OUZOUNIAN J.G. and KJOS S.L.: The accuracy of intrapartum ultrasonographic fetal weight estimation in diabetic pregnancies, Am. J. Obstet. Gynecol., 177: 503-6, 1997.

16- BEN-HAROUSH A., YOGEV Y., BAR J., et al.: Accuracy of sonographically estimated fetal weight in 840 women with different pregnancy complications prior to induction of labor, ultrasound Obstet. Gynecol., 23: 172-6, 2004.

17-MELAMED N., M.Sc., YARIV YOGEV, ISRAEL MEIZNER, REUVEN MASHIACH, RON BARDIN and AVI BEN-HAROUSH: Sonographic Fetal Weight Estimation Which Model Should Be Used? J. Ultrasound. Med., 28: 617-29, 2009.

18- CHIEN P.F., OWEN P. and KHAN K.S.: Validity of ultrasound estimation of fetal weight, Obstet. Gynecol., 95: 856-60, 2000.

19-NAHUM G.G. and STANISLAW H.: Hemoglobin, altitude and birth weight: Does maternal anemia during pregnancy influence fetal growth? J. Reprod. Med., Apr., 49 (4): 297-305. [Medline], 2004.

20- ATALIE COLMAN, DUSHYANT MAHARAJ, JOHN HUTTON and JEREMY TUOHY: Reliability of ultrasound estimation of fetal weight in term singleton pregnancies N.Z.M.J., 119: 1241. 214, 2006.

21- BAREL O., MAYMON R., VAKNIN Z., TOVBIN J. and SMORGICK N.: Sonographic fetal weight estimation-is there more to it than just fetal measurements? Prenat Diagn., Oct. 4. [Medline], 2013.

22- SABBAGHA R.E., MINOGUE J., TAMURA R.K. and HUNGERFORD S.A.: Estimation of birth weight by use of Ultrasonographic formulas targeted to large-, appropriate-, small-for-gestational-age fetuses. Am. J. Obstet.
Gynecol., 160: 854-60, 1989.

23- MARKUS HEER IVO and A CAROLIN KÜMPER A NADIN VOGTLE: Susanne Müller Egloff c Martin Dugas d Alexander Strauss Analysis of Factors Influencing the Ultrasonic Fetal Weight Estimation Ultrasound Obstet. Gynecol., 23: 204-10, 2008.

24- SIEMER F., EGGER N., HART N., MEURER B., MULLER A., DATHE O., GOECKE T. and SCHILD R.L.: Fetal weight estimation by ultrasound: Comparison of L1 different formulae and examiners with differing skill levels, Ultraschall Med., 29 (2): 759-64, 2008.

25- MARCO SCIOSCIA, M.D., ANTONELLA VIMERCATI, M.D., Ph.D., ORONZO CECI, M.D., MARIO VICINO, M.D., and LUIGI E. SELVAGGI, M.D.: Estimation of Birth Weight by Two-Dimensional Ultrasonography, Obstet. Gynecol., 111: 57-65, 2008.

26- HADLOCK F.P., HARRIST R.B., SHARMAN R.S., DETER R.L. and PARK S.K.: Estimation of fetal weight with the use of head, body and femur measurements-a prospective study, Am. J. Obstet. Gynecol., 151: 333-7, 1985.

27- IRINA BURD Ph.D., SINDHU SRINIVAS, M.S.C.E. EMMANUELLE PARÉ, VANITA DHARAN and EILEEN WANG: Is Sonographic Assessment of Fetal Weight Influenced by Formula Selection? J. Ultrasound Med., 28: 1019-24, 2009.

28- KUMARA and HEMANTHA PERERA: Evaluation of six commonly used formulae for sonographic estimation of fetal weight in a Sri Lankan population SriLankn, Journal of Obstetrics and Gynaecology, 3'L: 20-33, 2009.

29- CHAUHAN S.P., GROBMAN W.A., GHERMAN R.A., et al.: Suspicion and treatment of the macrosomic fetus: A review. Am. J. Obstet. Gynecol., 193: 332-46, 2005.

\section{دقة الموجات فوق الصوتية فى تقديروزن الجنين عند تماتم الصوتيل الحمل}

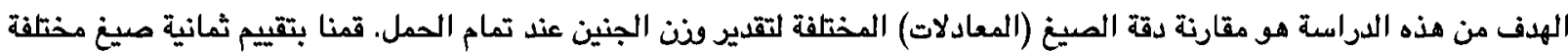

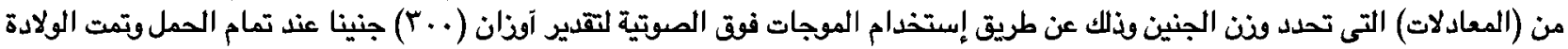

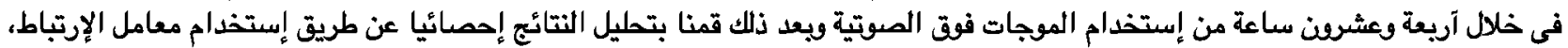

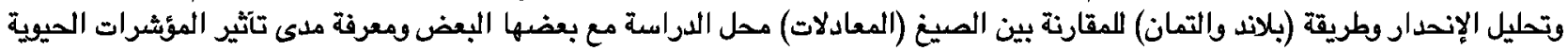

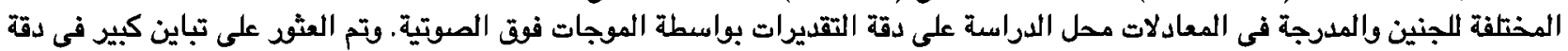

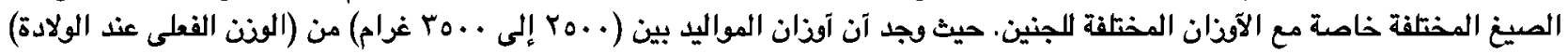

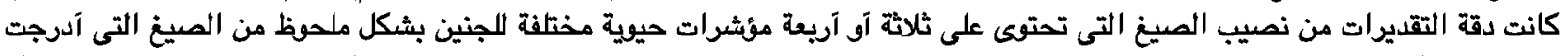

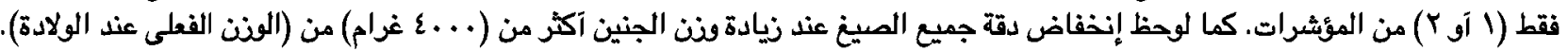

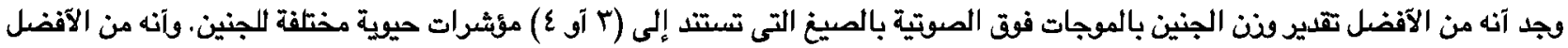

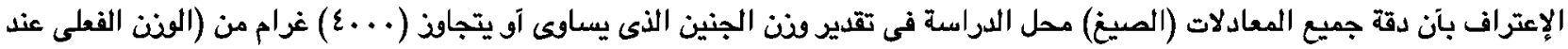

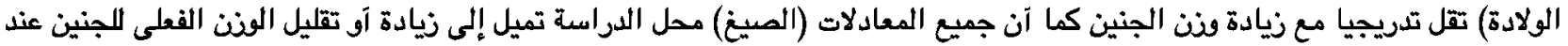

